\title{
Effect of Low-Level Laser on Bone Defects Treated with Bovine or Autogenous Bone Grafts: In Vivo Study in Rat Calvaria
}

\author{
Mércia J. S. Cunha, ${ }^{1,2,3}$ Luis A. Esper, ${ }^{2,3}$ Michyele C. Sbrana, ${ }^{2,3}$ Paula G. F. P. de Oliveira, ${ }^{1,3}$ \\ Accácio L. do Valle, ${ }^{3,4}$ and Ana Lúcia P. F. de Almeida ${ }^{3,4}$ \\ ${ }^{1}$ Hospital for Rehabilitation of Craniofacial Anomalies, University of São Paulo, Brazil \\ ${ }^{2}$ Bauru School of Dentistry, USP, Brazil \\ ${ }^{3}$ Faculdade de Odontologia de Bauru (FOB), Universidade de São Paulo (USP), Alameda Dr. Octávio Pinheiro Brisolla 9-75, \\ Vila Universitária, 17012901 Bauru, SP, Brazil \\ ${ }^{4}$ Department of Prosthodontics, Bauru School of Dentistry, USP, Brazil
}

Correspondence should be addressed to Ana Lúcia P. F. de Almeida; analmeida@usp.br

Received 28 February 2014; Revised 17 April 2014; Accepted 12 May 2014; Published 28 May 2014

Academic Editor: David M. Dohan Ehrenfest

Copyright (C) 2014 Mércia J. S. Cunha et al. This is an open access article distributed under the Creative Commons Attribution License, which permits unrestricted use, distribution, and reproduction in any medium, provided the original work is properly cited.

Objective. The purpose of this study was to histologically evaluate the effect of low-level laser (LLL) on the healing of critical size defects (CSD) in rat calvaria, filled with autogenous or inorganic bovine bone grafts. Methods. Sixty rats were divided into 6 groups $(n=10)$ : C (control—filled with blood clot), LLL (low-level laser-GaAlAs, $\lambda 780 \mathrm{~nm}, 100 \mathrm{~mW}, 210 \mathrm{~J} / \mathrm{cm}^{2}, \Phi 0.05 \mathrm{~cm}^{2} ; 6 \mathrm{~J} / \mathrm{point}$ ), $\mathrm{AB}$ (autogenous bone), ABL (autogenous bone + low-level laser), OB (inorganic bovine bone), and OBL (inorganic bovine bone + LLL). Material and Methods. The animals were killed after 30 days. Histological and histometric analyses were performed by light microscopy. Results. The groups irradiated with laser, LLL (47.67\% $\pm 8.66 \%)$, ABL (39.15\% $\pm 16.72 \%)$, and OBL (48.57\% \pm $28.22 \%)$, presented greater area of new bone formation than groups $\mathrm{C}(9.96 \% \pm 4.50 \%), \mathrm{AB}(30.98 \% \pm 16.59 \%)$, and $\mathrm{OB}(11.36 \%$ $\pm 7.89 \%$ ), which were not irradiated. Moreover, they were significantly better than group C (Kruskal-Wallis test followed by Dunn test, $P<0.05)$. Conclusion. The laser accelerated the healing of bone defects and the resorption of particles of the graft material.

\section{Introduction}

Currently, bone grafting has been widely used. It is estimated that approximately 2.2 million bone graft procedures are performed worldwide $[1,2]$ to repair defects in orthopedics, neurosurgery, and dentistry [2].

Among the graft materials used for bone regeneration, autogenous bone has been considered the ideal material $[1,3$, 4]. Even though it is the "gold standard" for reconstructions $[1,3,5]$, its collection is associated with 8.5 to $20 \%$ of complications, including hematoma [2], damage to anatomic structures [6], infections $[2,6]$, pain at the donor site $[7,8]$, and unpredictable graft resorption $[3,5]$.

For these reasons, several bone substitutes from different sources are available, with the advantages of unlimited supply and no need for a donor site. The inorganic bovine bone is the most researched graft material and is widely used in dentistry due to its similarity to human bone [3]. Promising results have been demonstrated by its use in clinical and animal studies $[9,10]$. Despite its excellent osteoconduction $[8,10]$, it lacks osteoinductive properties, which has encouraged researchers to find ways to further improve its behavior in vivo [9]. In addition, the use of low-level laser (LLL) has been studied as an alternative to speed healing in larger bone defects $[10,11]$.

The effects related to LLL include increased vascularity, increased osteoblastic activity [12], organization of collagen fibers, and changes in mitochondrial and intracellular levels of adenosine triphosphate $[12,13]$. It is a noninvasive method to stimulate osteogenesis $[13,14]$ and accelerate the healing of bone defects [12-14].

Positive $[11,13,15]$ and negative $[16,17]$ results have been reported in both in vivo and in vitro studies $[11,15]$ regarding the repair of soft or mineralized tissue $[18,19]$, but few 
studies have evaluated the role of LLL associated with bone substitutes [20,21].

Therefore, the purpose of this study was to histologically evaluate the effect of low-level laser on the healing of critical size defects (CSD) in rat calvaria, filled with autogenous or inorganic bovine bone grafts.

\section{Material and Methods}

2.1. Experimental Design. The experimental protocol was approved by the Institutional Review Board on Animal Studies of Bauru School of Dentistry, University of São Paulo.

A total of 60 male rats (Rattus norvegicus, albinus, Wistar) weighing between 250 and $300 \mathrm{~g}$ were utilized. The animals were maintained in an environment with 12-hour cycle of light per day and temperature between 22 and $24^{\circ} \mathrm{C}$. Throughout the experiment, the animals received selected solid diet and water ad libitum. The animals were randomly assigned to the following experimental groups $(n=10)$ : (1) group C-control defect filled with blood clot; (2) group LLL-LLL (Theralase DMC, São Carlos, Brazil); (3) group $\mathrm{AB}$-autogenous bone; (4) group $\mathrm{ABL}$-autogenous bone + LLL; (5) group OB-inorganic bovine bone/0.25-1 mm (Bio-Oss-Geistlich Pharma AG, Wolhusen, Switzerland); (6) group OBL-inorganic bovine bone + LLL.

2.2. Surgical Procedure. The animals were anesthetized by an intramuscular injection of xylazine $(0.02 \mathrm{~mL} / \mathrm{kg})$ and ketamine hydrochloride $(0.4 \mathrm{~mL} / \mathrm{kg})$. After trichotomy and antisepsis of the dorsal part of the skull of each animal, a semilunar incision was made in the calvaria and a fullthickness flap was raised in posterior direction. A $5 \mathrm{~mm}$ diameter CSD was created with a trephine at low speed under thorough irrigation with sterile saline. The defect included a portion of the sagittal suture. The dura mater and the brain were preserved during craniotomy. The full thickness of parietal bone was gently removed $[13,22]$.

With the aid of a previously made surgical guide, two Lshaped marks were made, one being at $2 \mathrm{~mm}$ anteriorly and the other one being at $2 \mathrm{~mm}$ posteriorly to the margins of the surgical defect, with a FG-700 truncated carbide cone bur under continuous irrigation with sterile saline and then filled with amalgam $[13,22]$.

The major axis of each "L" was located on a craniocaudal longitudinal imaginary line that divided the surgical defect into half. These markings were useful to identify the middle of the original surgical defect during laboratory processing and also to locate the original bone margins during histometric analysis $[13,22]$.

After fabrication of the L-shaped mark, the defect was filled according to each group. In group C, it was only filled with blood clot. Group LLL was filled with blood clot and was submitted to LLL application. In group $\mathrm{OB}$, the defects were filled with $0.02 \mathrm{~g}$ of inorganic bovine bone, and group OBL was filled with the same amount of inorganic bovine bone followed by LLL application. In group AB, the calvaria defect was filled with autogenous bone obtained from ground calvaria bone harvested with the trephine; the same was performed for group ABL, which was thereafter submitted to LLL application.

To standardize the amount of $\mathrm{OB}$ used in each defect, the $\mathrm{AB}$ was removed from the ground calvaria using a syringe with millimeter markings and weighed on a precision scale. The same weight $(0.02 \mathrm{~g})$ and volume $\left(1 \mathrm{~mm}^{3}\right)$ were used for the OB.

The flap was then repositioned and sutured with 4-0 silk suture. Each animal received an intramuscular injection of 24,000 units of penicillin G-benzathine.

All surgical procedures were performed by a single operator, previously trained in a previous study [13].

2.3. Protocol of Low-Level Laser Therapy. The laser used was Theralase DMC (GaAlAs, $\lambda=780 \mathrm{~nm}, 100 \mathrm{~mW}, \Phi 0.05 \mathrm{~cm}^{2}$, $210 \mathrm{~J} / \mathrm{cm}^{2}$ of energy density, $60 \mathrm{~s} /$ point, $6 \mathrm{~J} /$ point, continuous mode). The applications were made at four points on the surgical wound surface following a clockwise direction ( $12 \mathrm{~h}$, $3 \mathrm{~h}, 6 \mathrm{~h}$, and $9 \mathrm{~h}$ positions) and a central point [13]. In the LLL group, application was performed after filling with blood clot, while in the other groups application was performed after insertion of the respective graft material ( $\mathrm{AB}$ and $\mathrm{OB})$.

2.4. Tissue Processing. The animals were killed at 30 days postoperatively with $5 \mathrm{mg} / \mathrm{mL}$ of the association of ketamine and xylazine. The original surgical defect area and surrounding tissues were removed en bloc. The specimens were fixed in $10 \%$ formalin solution, rinsed in water, and decalcified in an $18 \%$ ethylene diamine tetraacetic acid solution.

After decalcification, each specimen was longitudinally divided into two blocks, exactly over the center of the original surgical defect, using the main axes of each amalgam marking as reference. In addition, cross-sections were performed tangentially to the lowest axis on both "L" markings, so that the end of each specimen measured $9 \mathrm{~mm}$ in length. This allowed accurate determination of the boundaries of the original surgical defect during histometric analysis [13, 22].

The specimens were then processed and embedded in paraffin. Longitudinal serial sections with $6 \mu \mathrm{m}$ thickness were obtained starting from the center of the original surgical defect. The sections were stained with hematoxylin and eosin (HE) for light microscopy analysis.

2.5. Histomorphometric Analysis. The histological and histometric analyses were performed by a previously calibrated examiner blinded to the experimental groups. Four histological sections were selected, representing the central area of the original surgical defect. Images of the histological sections were captured by a digital camera SPOT RT3-2540 Color Slider 2.0 MP connected to the Olympus BX50 microscope at $2 \mathrm{x}$ magnification and saved on a computer. For each animal, new bone formation (NBF) values were calculated by the arithmetic mean of three most central histological sections of the calvaria, and another section was used for histological analysis. The histometric analysis was performed on the ImageLab 2000 software (Bio Diracon Informática Ltd., Vargem Grande do Sul, SP, Brazil) [13, 22]. 


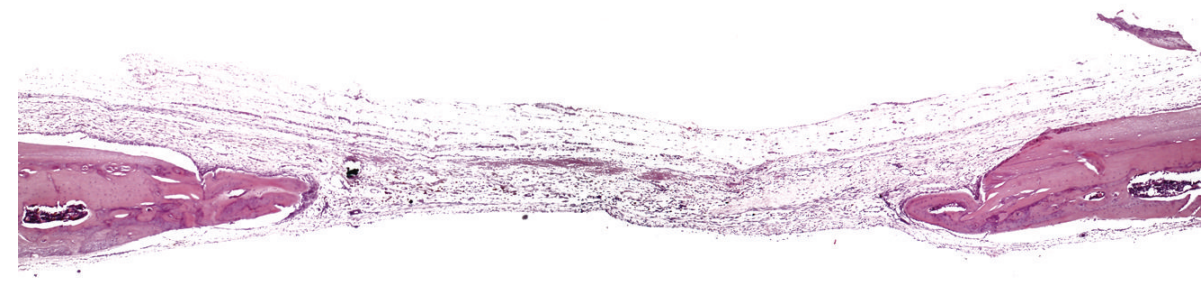

(a)

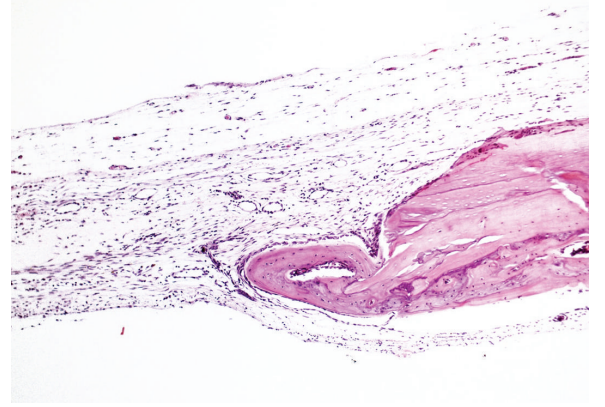

(b)

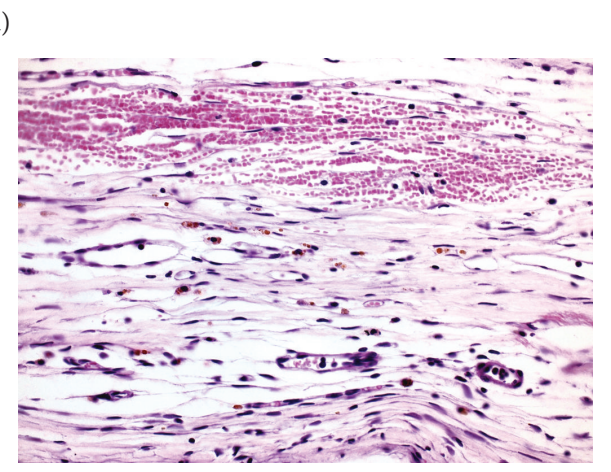

(c)

Figure 1: Photomicrographs of group C. (a) Panoramic view of the defect (4x); (b) defect filled with bundles of collagen fibers (40x); (c) small amount of newly formed bone (asterisk) along the margins of the surgical defect (10x). Hematoxylin and eosin.

The following criteria, based on the methodology proposed by Furlaneto et al. [22], were followed to standardize the histometric analysis.

(1) The total area (TA) to be analyzed corresponded to the total area of the original surgical defect. This area was determined by identifying the external and internal surfaces of the original calvaria and the left and right margins of the surgical defect. These surfaces were connected with lines drawn following their respective curvatures. Considering the total length of the histological specimen $(9 \mathrm{~mm}), 2 \mathrm{~mm}$ was measured from the left and right ends of the specimen toward the center in order to determine the boundaries of the original surgical defect.

(2) The area of new bone formation (NBF) and the remaining particle areas (RPA) of the implanted materials were delineated within the boundaries of the TA.

(3) The TA was measured in $\mathrm{mm}^{2}$ and $100 \%$ of the area being analyzed was considered. The NBF and RPA were also measured in $\mathrm{mm}^{2}$ and calculated as percentages of TA in accordance with the following formula: $\operatorname{NBF}\left(\mathrm{mm}^{2}\right) / \mathrm{TA}\left(\mathrm{mm}^{2}\right) \times 100$.

2.6. Statistical Analysis. For each animal, the values of NBF and RPA were represented by the arithmetic mean of the four most central histological sections of the calvaria. The values found did not pass the normality test (Shapiro-Wilk). Thus, they were subjected to the nonparametric KruskalWallis test followed by the Dunn test. Analysis of the statistical test power was verified with a minimum power of 0.86 . The differences were considered statistically significant when $P<$ 0.05 , at a confidence level of $95 \%$.

\section{Results}

During the laboratory processing, 1 specimen from group C, 3 specimens from group LLL, 1 specimen from group $A B$, and 2 specimens from group $\mathrm{ABL}$ were lost.

3.1. Qualitative Histological Analysis. In all groups absence of inflammatory infiltrate was observed.

In group $\mathrm{C}$, virtually the entire length of the surgical wound was filled by connective tissue with collagen fibers orientated parallel to the wound surface. A small amount of new bone formation was observed along the margins of the surgical defect (Figure 1). Complete regenerated bone repair of the defect did not occur in any specimen.

New bone formation surrounded by an osteoid matrix was observed in some specimens in group LLL. The tissues presented parallel oriented bundles of collagen fibers and absence of inflammatory infiltrate. New bone formation extending linearly toward the center of the original defect was observed in two specimens. Areas of remodeled bone were also observed at the region of old bone, which was preserved (Figure 2).

In group $\mathrm{AB}$, the connective tissue was well organized within the surgical defect, with formation of osteoid matrix, presence of fibroblasts, and absence of inflammatory infiltrate. The new bone formation was present in variable extensions at the margins of the defect and around the grafted 


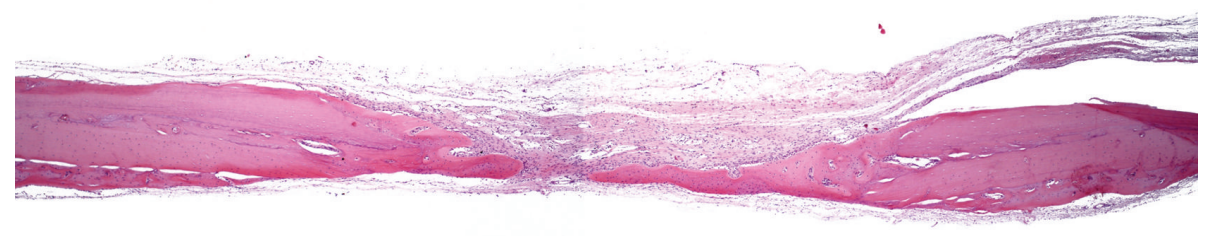

(a)

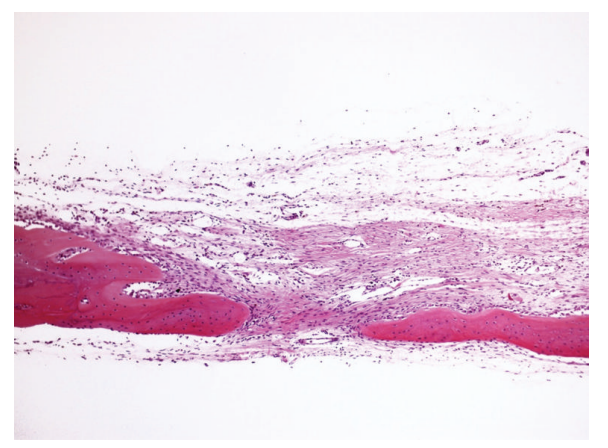

(b)

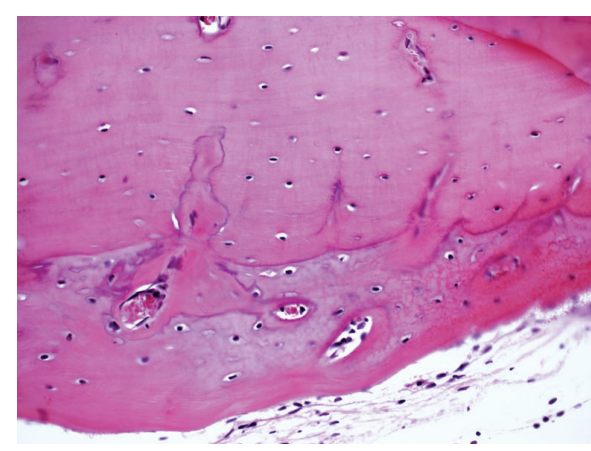

(c)

Figure 2: Photomicrographs of group LLL. (a) Panoramic view of the surgical defect (4x); (b) bone formation extending toward the center of the original surgical defect (10x); (c) bone remodeling in the region of old bone that was preserved (40x). Hematoxylin and eosin.



(a)

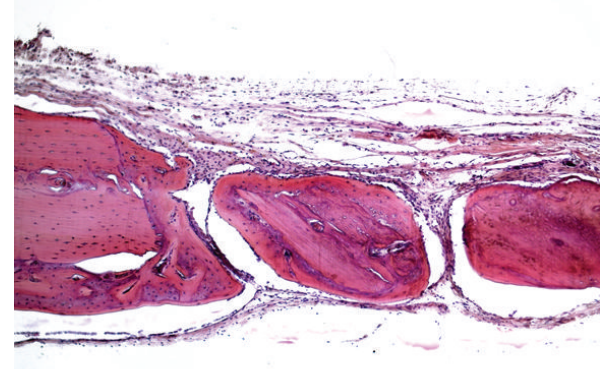

(b)

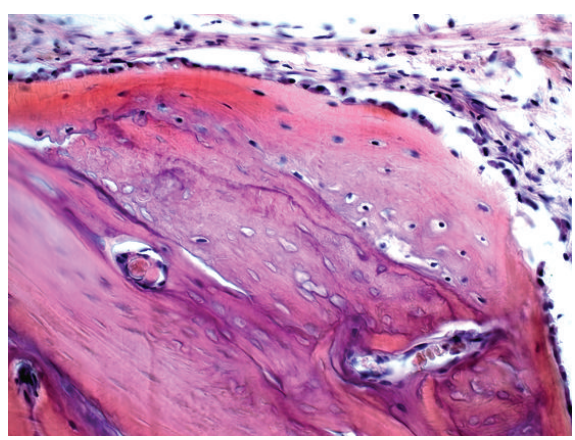

(c)

Figure 3: Photomicrographs of group AB. (a) Panoramic view of the surgical defect (4x); (b) newly formed bone tissue along the margins of the surgical defect and bone graft particles (10x); (c) autogenous bone particle surrounded by new bone formation (40x).

bone particles (Figure 3). In only one specimen, bone graft particles were not observed.

The osteoid matrix was observed in all specimens in group ABL. New bone formation was present in variable extensions. Three specimens (37.5\%) showed new bone formation toward the center of the surgical defect. Grafted bone particles were also observed, most of which had new bone tissue at the periphery (Figure 4). 




(a)

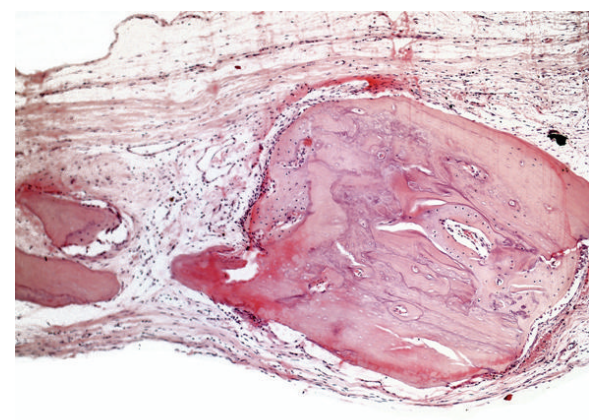

(b)

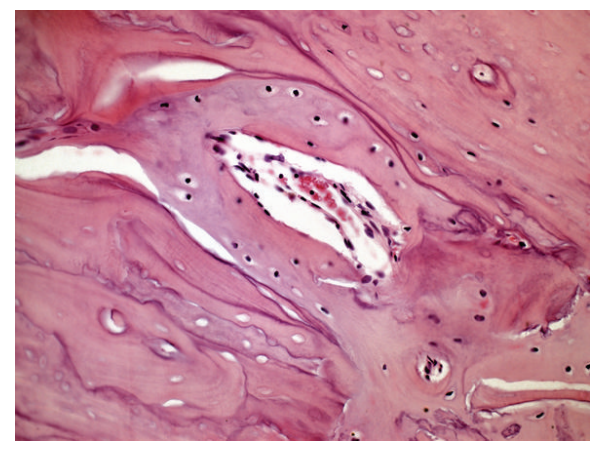

(c)

FIgURE 4: Photomicrographs of group ABL. (a) Panoramic view of the surgical defect (4x); (b) autogenous bone particles with new bone formation at the periphery (10x); (c) area of new formation and remodeling of the autogenous bone particle (40x).

TABLE 1: Means and standard deviations of the amount of newly formed bone.

\begin{tabular}{|c|c|c|c|c|c|c|}
\hline Groups & $N$ & Mean & Standard deviation (sd) & Q25 & Median & Q75 \\
\hline $\mathrm{C}^{\mathrm{a}}$ & 9 & 9.96 & 4.50 & 8.58 & 9.52 & 13.33 \\
\hline $\mathrm{L}^{\mathrm{b}}$ & 7 & 4.67 & 8.66 & 43.96 & 44.58 & 55.41 \\
\hline$A B^{a, b}$ & 9 & 30.98 & 16.59 & 20.96 & 25.10 & 36.24 \\
\hline $\mathrm{ABL}^{\mathrm{b}}$ & 8 & 39.15 & 16.72 & 26.89 & 40.41 & 53.32 \\
\hline $\mathrm{BO}^{\mathrm{a}}$ & 10 & 11.36 & 7.89 & 6.30 & 9.49 & 11.57 \\
\hline $\mathrm{BOL}^{\mathrm{b}}$ & 10 & 48.57 & 28.22 & 35.76 & 42.22 & 74.66 \\
\hline
\end{tabular}

Same letters represent no statistical difference (significance level of $5 \%$ ).

In $\mathrm{OB}$ group, parallel oriented collagen fibers were observed. Inorganic bovine bone particles were present, many with osteoclasts in their periphery. In most specimens there was a slight bone formation at the margins of the defect (Figure 5).

Two specimens in group $\mathrm{OB}$ presented new bone formation extending toward the center of the defect, maintaining the original thickness of the calvaria. New bone tissue and osteoclasts were observed at the periphery of the remaining inorganic bovine bone particles. Inflammatory infiltrate was not observed (Figure 6).

3.2. Histomorphometric and Statistical Analysis. The groups irradiated with LLL showed higher NBF averages. Correlations were statistically significant $(P<0.05)$ between groups $\mathrm{OB} \times \mathrm{OBL} ; \mathrm{LLL} \times \mathrm{OB} ; \mathrm{OB} \times \mathrm{ABL} ; \mathrm{OBL} \times \mathrm{C} ; \mathrm{C} \times \mathrm{LLL} ; \mathrm{C} \times \mathrm{ABL}$ (Table 1, Figure 7).
The groups irradiated with LLL had lower RPA averages. There was statistically significant difference $(P<0.05)$ between $\mathrm{OB} \times \mathrm{OBL}$ and $\mathrm{OB} \times \mathrm{ABL}$ groups (Table 2, Figure 8 ).

\section{Discussion}

The improvement of vascularization after LLL in this study is one of the possible mechanisms for the clinical efficacy of that treatment $[12,13,23-25]$. It has also been reported that LLL increases the osteoblast and osteoclast activity [26] and stimulates production of the bone matrix and the formation of bone callus $[25,27]$ but also accelerates the dynamics of the bone matrix by modifying the expression of the extracellular matrix components and increasing the area of new bone formation, which reduces the time necessary for bone healing [28]. 
TABLE 2: Means and standard deviations of the remaining particle.

\begin{tabular}{lcccccc}
\hline Groups & $N$ & Mean & Standard deviation (sd) & Q25 & Median & Q75 \\
\hline $\mathrm{AB}^{\mathrm{a}, \mathrm{b}}$ & 9 & 9.16 & 7.10 & 4.35 & 1.04 & 13.46 \\
$\mathrm{ABL}^{\mathrm{b}}$ & 8 & 3.66 & 2.79 & 35.72 & 5.04 & 3.84 \\
$\mathrm{BO}^{\mathrm{a}}$ & 10 & 38.73 & 6.95 & 15.25 & 0.00 & 2.71 \\
$\mathrm{BOL}^{\mathrm{b}}$ & 10 & 16.74 & & & 22.42 & 28.23 \\
\hline
\end{tabular}

Same letters represent no statistical difference (significance level of 5\%).

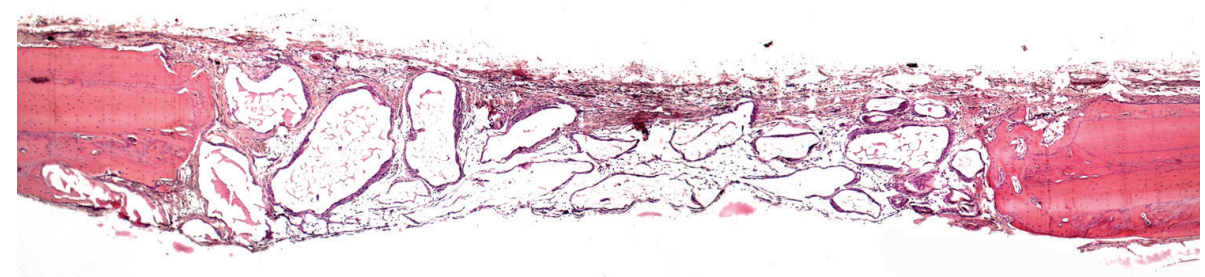

(a)

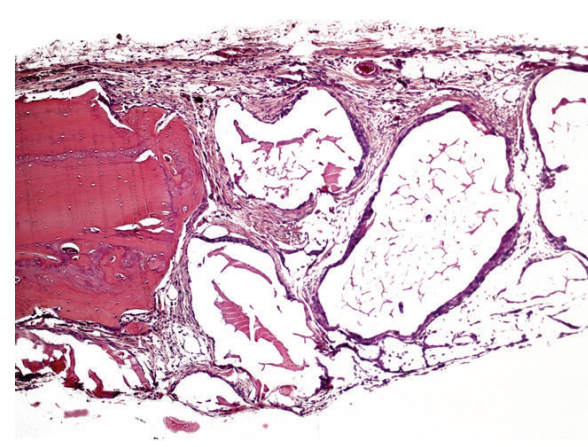

(b)

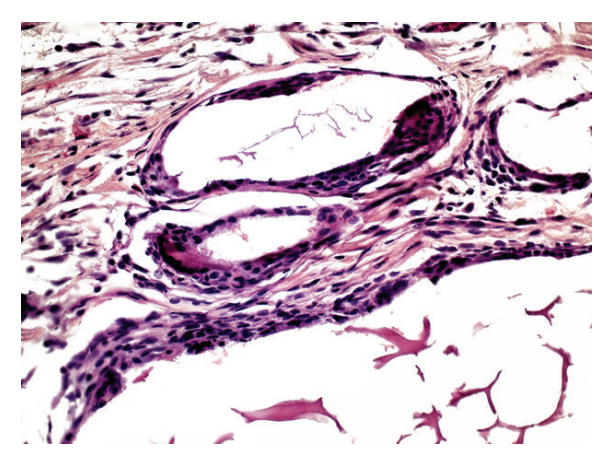

(c)

FIgURE 5: Photomicrographs of group OB. (a) Panoramic view of the surgical defect (4x); (b) bone formation along the margins of the defect $(10 \mathrm{x})$; (c) osteoclasts in the vicinity of bovine bone graft particles (40x).

Another explanation for the accelerated bone healing observed for groups irradiated with LLL is that the undifferentiated mesenchymal cells can be positively biomodulated to become osteoblasts and evolve to osteocytes faster. It is known that the osteogenic potential of the mesenchymal cells depends, in addition to genetic factors, on induced local and systemic factors. LLL could act as such an inductor factor $[24,29,30]$.

It has been reported that the biomodulation of the LLL depends on the wavelength used, since tissue components can influence the dispersion of light $[12,23,29]$. In the infrared spectrum the laser can provide increased osteoblast proliferation, collagen deposition, and bone formation [12, 29]. In this study, there was greater bone formation in the group irradiated with laser (group LLL) compared to the nonirradiated group (group C).

There are no universally accepted parameters for using the LLL. Different irradiation protocols are found with different activation materials, wavelengths, and even dose and number of applications, precluding the comparison of results and choice of treatment parameters [31]. Similar to previous studies $[13,15]$, this work intended to establish guidelines for a transoperative protocol immediately involving a single laser application in direct contact with the wound area and confirmed the beneficial effects of a single session irradiation for bone healing of the defect, demonstrating that this type of treatment may be feasible, easy, and fast.

When evaluating the area of new bone formation in this study, the results for groups irradiated with LLL were similar to the $\mathrm{AB}$ and $\mathrm{ABL}$ groups. This would suggest that only the application of laser would already be beneficial in bone regeneration with this application protocol. Moreover, the association of $\mathrm{AB}$ and LLL showed superior results when compared to the treatment with $\mathrm{AB}$ alone. The lack of statistically significant difference between the $\mathrm{AB}$ and $\mathrm{ABL}$ groups can be assigned to the fact that autogenous bone alone can already be considered a very good grafting material. Starting from a high level of excellence, the laser would not be able to add benefits to the point that it would be statistically different.

Although no statistically significant difference was observed in the NBF and RPA between groups $A B$ and 


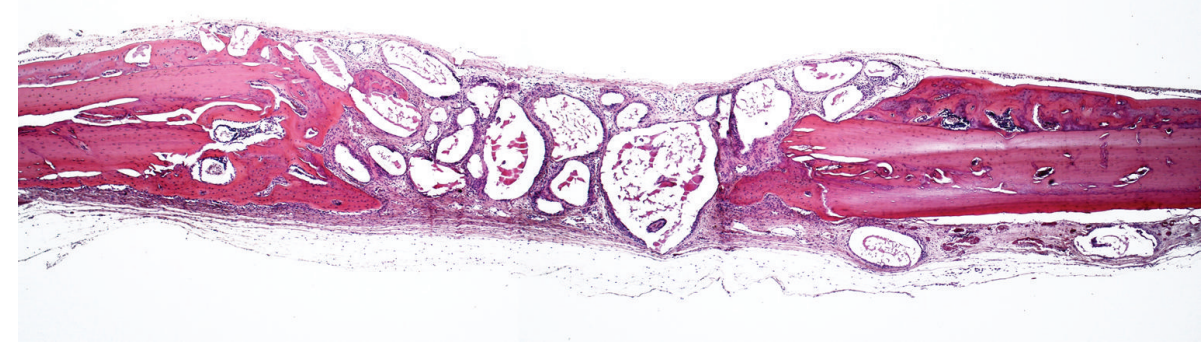

(a)

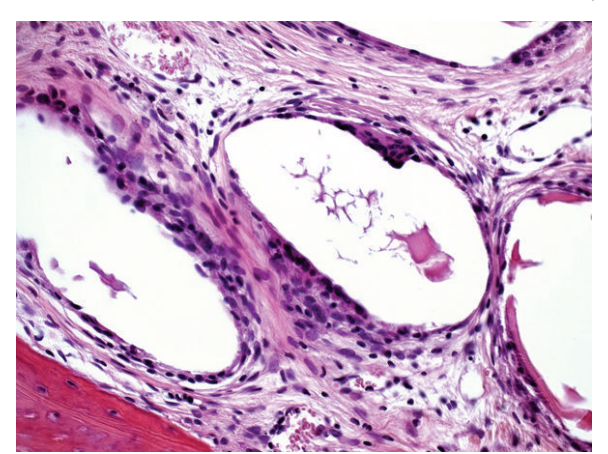

(b)

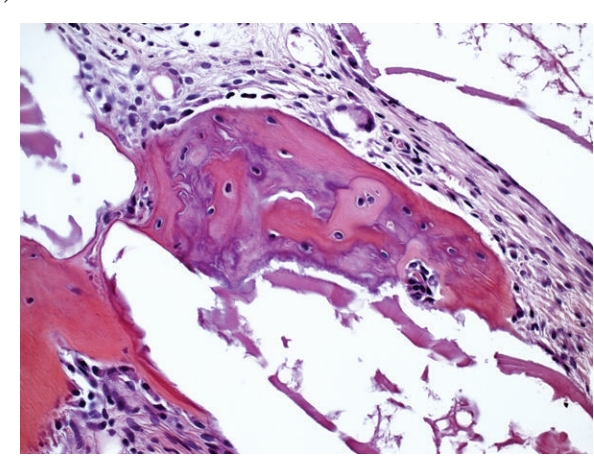

(c)

FIgure 6: Photomicrographs of group OB. (a) Panoramic view of the surgical defect (4x); (b) bone formation along the margins of the defect $(10 \mathrm{x}) ;(\mathrm{c})$ osteoclasts in the vicinity of bovine bone graft particles (40x).

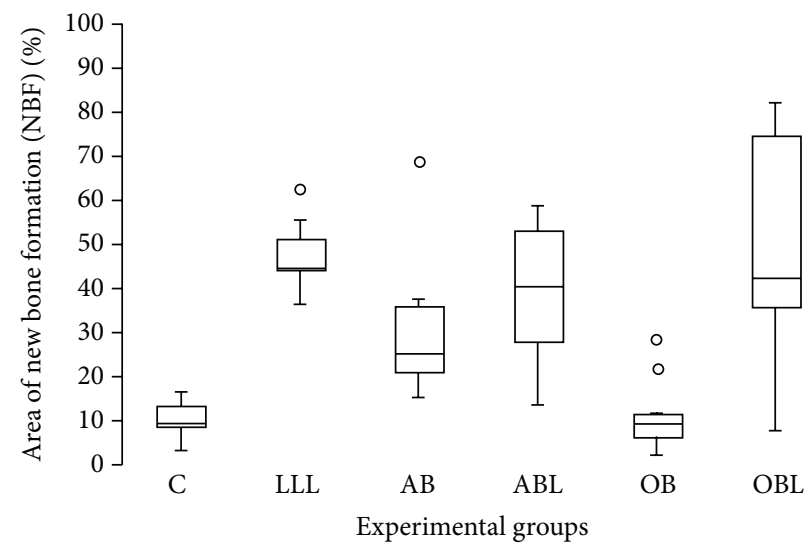

FIGURE 7: Distribution of new bone formation area for all experimental groups.

$\mathrm{ABL}$, it is believed that the laser has also been able to speed up the process of bone remodeling when the allograft was used, since the histological analysis revealed that, in the irradiated group, there were specimens with new bone formation toward the center of the surgical defect, and most graft particles showed new bone formation at the periphery. Thus, the association of LLL and AB could be suggested as advantageous to accelerate cell proliferation and increase the new bone volume, thus aiding the integration of the graft into the recipient area, corroborating the findings of other studies $[13,14,23]$. This is recommended as an additional treatment modality in the regeneration of bone defects, since it is a noninvasive method to stimulate osteogenesis [14] and accelerate the healing of bone defects [12-14].
The resorption of inorganic bovine bone particles is still a conflicting issue in the literature. There are reports that particles in the interior of bone defects fail to resorb and remain like a motionless body surrounded by the host bone [31, 32]. Moreover, after months of healing, osteoblastic activity is observed in the particles and it is believed that, with time, these particles remodel themselves and meanwhile the new bone is formed; however, it appears to be a slow process [33]. It is believed that the laser has accelerated the process of bone formation and resorption of such particles, since the OBL group showed a statistically significant difference in the NBF and RPA when compared to the OB. This may be due to the fact that the laser improves vascularization [12, 23-25], increases the osteoclastic [26] and osteoblastic activity [12], 


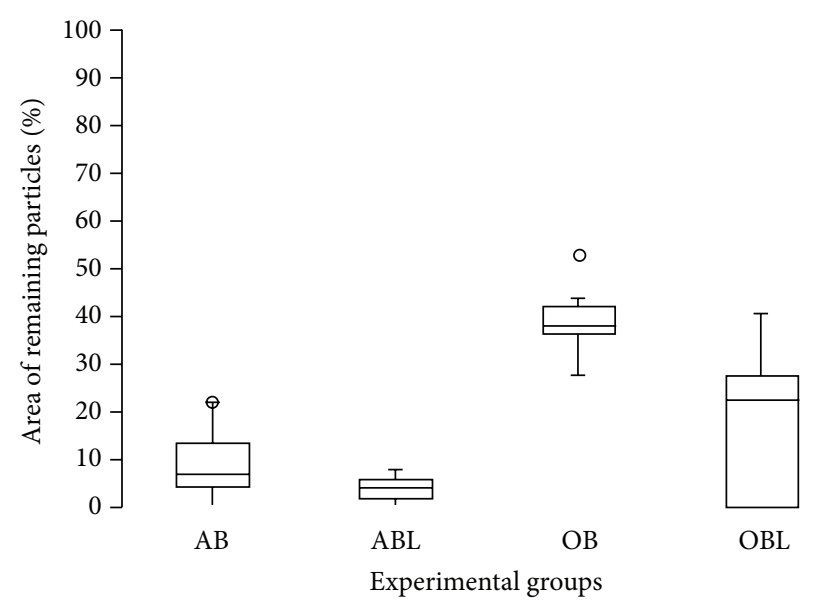

FIGURE 8: Distribution of area of the remaining particle for groups receiving graft material.

stimulates the production of the bone matrix [34], and can act as an osteoinductive factor [24, 29].

In the present study, the fact that all groups irradiated with LLL presented superior results to group C and groups receiving only grafts suggests that this type of therapy may be effective in the healing of bone defects, especially when associated with a filling material.

\section{Conclusion}

The LLL accelerated the healing of bone defects and the resorption of the graft material particles.

\section{Conflict of Interests}

The authors declare that there is no conflict of interests regarding the publication of this paper.

\section{Acknowledgment}

The authors would like to thank São Paulo Research Foundation (FAPESP) for the Master's Scholarship (2010/13170-3) and for the Research Grant (2010/10538-0).

\section{References}

[1] K.-U. Lewandrowski, J. D. Gresser, D. L. Wise, and D. J. Trantolo, "Bioresorbable bone graft substitutes of different osteoconductivities: a histologic evaluation of osteointegration of poly(propylene glycol-co-fumaric acid)-based cement implants in rats," Biomaterials, vol. 21, no. 8, pp. 757-764, 2000.

[2] P. V. Giannoudis, H. Dinopoulos, and E. Tsiridis, "Bone substitutes: an update," Injury, vol. 36, no. 3, pp. S20-S27, 2005.

[3] M. Hallman and A. Thor, "Bone substitutes and growth factors as an alternative/complement to autogenous bone for grafting in implant dentistry," Periodontology 2000, vol. 47, no. 1, pp. 172192, 2008.

[4] C. M. Schmitt, H. Doering, T. Schmidt, R. Lutz, F. W. Neukam, and K. A. Schlegel, "Histological results after maxillary sinus augmentation with Straumann BoneCeramic, Bio-Oss, Puros, and autologous bone. A randomized controlled clinical trial," Clinical Oral Implants Research, vol. 24, no. 5, pp. 576-585, 2013.

[5] G. F. Rogers and A. K. Greene, "Autogenous bone graft: basic science and clinical implications," Journal of Craniofacial Surgery, vol. 23, no. 1, pp. 323-327, 2012.

[6] A. S. Herford and J. S. Dean, "Complications in bone grafting," Oral and Maxillofacial Surgery Clinics of North America, vol. 23, no. 3, pp. 433-442, 2011.

[7] P. Amerio, G. Vianale, M. Reale, R. Muraro, A. Tulli, and A. Piattelli, "The effect of deproteinized bovine bone on osteoblast growth factors and proinflammatory cytokine production," Clinical Oral Implants Research, vol. 21, no. 6, pp. 650-655, 2010.

[8] L. Ohayon, "Ridge enlargement using deproteinized bovine bone and a bioresorbable collagen membrane: a tomodensitometric, histologic, and histomorphometric analysis," The International Journal of Periodontics \& Restorative Dentistry, vol. 31, no. 3, pp. 237-245, 2011.

[9] J. Torres, F. M. Tamimi, I. F. Tresguerres et al., "Effect of solely applied platelet-rich plasma on osseous regeneration compared to Bio-Oss: a morphometric and densitometric study on rabbit calvaria," Clinical Implant Dentistry and Related Research, vol. 10, no. 2, pp. 106-112, 2008.

[10] E. Fávaro-Pípi, D. A. Ribeiro, J. U. Ribeiro et al., "Low-level laser therapy induces differential expression of osteogenic genes during bone repair in rats," Photomedicine and Laser Surgery, vol. 29, no. 5, pp. 311-317, 2011.

[11] A. N. S. Júnior, A. L. Pinheiro, M. G. Oliveira, R. Weismann, L. M. Ramalho, and R. A. Nicolau, "Computerized morphometric assessment of the effect of low-level laser therapy on bone repair: an experimental animal study," Journal of Clinical Laser Medicine \& Surgery, vol. 20, no. 2, pp. 83-87, 2002.

[12] D. Barbosa, R. A. de Souza, M. Xavier, F. F. da Silva, E. Â. Arisawa, and A. G. J. B. Villaverde, "Effects of low-level laser therapy (LLLT) on bone repair in rats: optical densitometry analysis," Lasers in Medical Science, vol. 28, no. 2, pp. 651-656, 2013.

[13] A. L. P. F. de Almeida, I. L. Medeiros, M. J. S. Cunha, M. C. Sbrana, P. G. F. de Oliveira, and L. A. Esper, "The effect of lowlevel laser on bone healing in critical size defects treated with or without autogenous bone graft: an experimental study in rat calvaria," Clinical Oral Implants Research, 2013. 
[14] R. V. da Silva and J. A. Camilli, "Repair of bone defects treated with autogenous bone graft and low-power laser," Journal of Craniofacial Surgery, vol. 17, no. 2, pp. 297-301, 2006.

[15] H. Pretel, R. F. Z. Lizarelli, and L. T. O. Ramalho, "Effect of lowlevel laser therapy on bone repair: histological study in rats," Lasers in Surgery and Medicine, vol. 39, no. 10, pp. 788-796, 2007.

[16] E. J. Luger, S. Rochkind, Y. Wollman, G. Kogan, and S. Dekel, "Effect of low-power laser irradiation on the mechanical properties of bone fracture healing in rats," Lasers in Surgery and Medicine, vol. 22, no. 2, pp. 97-102, 1998.

[17] G. Anneroth, G. Hall, H. Rydén, and L. Zetterqvist, "The effect of low-energy infra-red laser radiation on wound healing in rats," British Journal of Oral and Maxillofacial Surgery, vol. 26, no. 1, pp. 12-17, 1988.

[18] A. Stein, D. Benayahu, L. Maltz, and U. Oron, "Low-level laser irradiation promotes proliferation and differentiation of human osteoblasts in vitro," Photomedicine and Laser Surgery, vol. 23, no. 2, pp. 161-166, 2005.

[19] A. Leonida, A. Paiusco, G. Rossi, F. Carini, M. Baldoni, and G. Caccianiga, "Effects of low-level laser irradiation on proliferation and osteoblastic differentiation of human mesenchymal stem cells seeded on a three-dimensional biomatrix: in vitro pilot study," Lasers in Medical Science, vol. 28, no. 1, pp. 125-132, 2013.

[20] A. L. B. Pinheiro, F. D. A. L. Limeira Júnior, M. E. M. Gerbi, L. M. P. Ramalho, C. Marzola, and E. A. C. Ponzi, "Effect of low level laser therapy on the repair of bone defects grafted with inorganic bovine bone," Brazilian Dental Journal, vol. 14, no. 3 , pp. 177-181, 2003.

[21] A. L. B. Pinheiro, L. G. P. Soares, A. F. S. Barbosa, L. M. P. Ramalho, and J. N. dos Santos, "Does LED phototherapy influence the repair of bone defects grafted with MTA, bone morphogenetic proteins, and guided bone regeneration? A description of the repair process on rodents," Lasers in Medical Science, vol. 27, no. 5, pp. 1013-1024, 2012.

[22] F. A. C. Furlaneto, M. J. H. Nagata, S. E. Fucini, T. M. Deliberador, T. Okamoto, and M. R. Messora, "Bone healing in critical-size defects treated with bioactive glass/calcium sulfate: a histologic and histometric study in rat calvaria," Clinical Oral Implants Research, vol. 18, no. 3, pp. 311-318, 2007.

[23] J. B. B. Weber, A. L. B. Pinheiro, M. G. de Oliveira, F. A. M. Oliveira, and L. M. P. Ramalho, "Laser therapy improves healing of bone defects submitted to autologus bone graft," Photomedicine and Laser Surgery, vol. 24, no. 1, pp. 38-44, 2006.

[24] N. S. Aboelsaad, M. Soory, L. M. A. Gadalla et al., "Effect of soft laser and bioactive glass on bone regeneration in the treatment of infra-bony defects (a clinical study)," Lasers in Medical Science, vol. 24, no. 3, pp. 387-395, 2009.

[25] Y. Ozawa, N. Shimizu, G. Kariya, and Y. Abiko, "Low-energy laser irradiation stimulates bone nodule formation at early stages of cell culture in rat calvarial cells," Bone, vol. 22, no. 4, pp. 347-354, 1998.

[26] R. A. Nicolau, V. Jorgetti, J. Rigau, M. T. T. Pacheco, L. M. dos Reis, and R. A. Zangaro, "Effect of low-power GaAIAs laser $(660 \mathrm{~nm})$ on bone structure and cell activity: an experimental animal study," Lasers in Medical Science, vol. 18, no. 2, pp. 8994, 2003.

[27] S. K. Shakouri, J. Soleimanpour, Y. Salekzamani, and M. R. Oskuie, "Effect of low-level laser therapy on the fracture healing process," Lasers in Medical Science, vol. 25, no. 1, pp. 73-77, 2010.

[28] L. A. D. S. Merli, V. P. de Medeiros, L. Toma et al., "The low level laser therapy effect on the remodeling of bone extracellular matrix," Photochemistry and Photobiology, vol. 88, no. 5, pp. 1293-1301, 2012.

[29] A. L. B. Pinheiro and M. E. M. M. Gerbi, "Photoengineering of bone repair processes," Photomedicine and Laser Surgery, vol. 24, no. 2, pp. 169-178, 2006.

[30] L. Abramovitch-Gottlib, T. Gross, D. Naveh et al., "Low level laser irradiation stimulates osteogenic phenotype of mesenchymal stem cells seeded on a three-dimensional biomatrix," Lasers in Medical Science, vol. 20, no. 3-4, pp. 138-146, 2005.

[31] J. P. da Silva, M. A. da Silva, A. P. F. Almeida, I. Lombardi Junior, and A. P. Matos, "Laser therapy in the tissue repair process: a literature review," Photomedicine and Laser Surgery, vol. 28, no. 1, pp. 17-21, 2010.

[32] R. Ewers, W. Goriwoda, C. Schopper, D. Moser, and E. Spassova, "Histologic findings at augmented bone areas supplied with two different bone substitute materials combined with sinus floor lifting," Clinical Oral Implants Research, vol. 15, no. 1, pp. 96100, 2004.

[33] T. Berglundh and J. Lindhe, "Healing around implants placed in bone defects treated with Bio-Oss: an experimental study in the dog," Clinical Oral Implants Research, vol. 8, no. 2, pp. 117-124, 1997.

[34] K. M. AlGhamdi, A. Kumar, and N. A. Moussa, "Low-level laser therapy: a useful technique for enhancing the proliferation of various cultured cells," Lasers in Medical Science, vol. 27, no. 1, pp. 237-249, 2012. 



Submit your manuscripts at http://www.hindawi.com
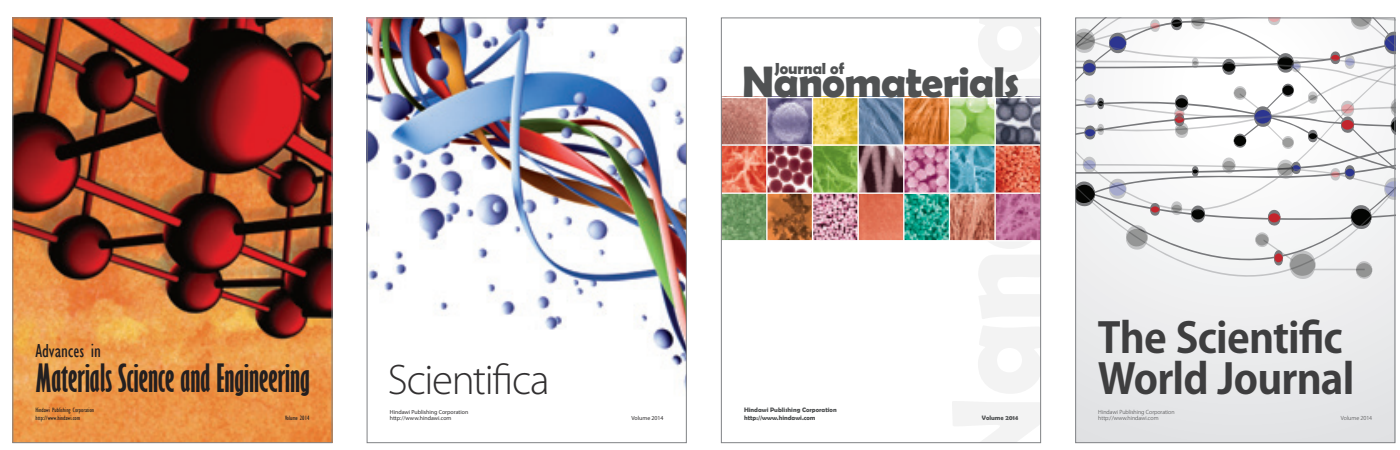

\section{The Scientific World Journal}
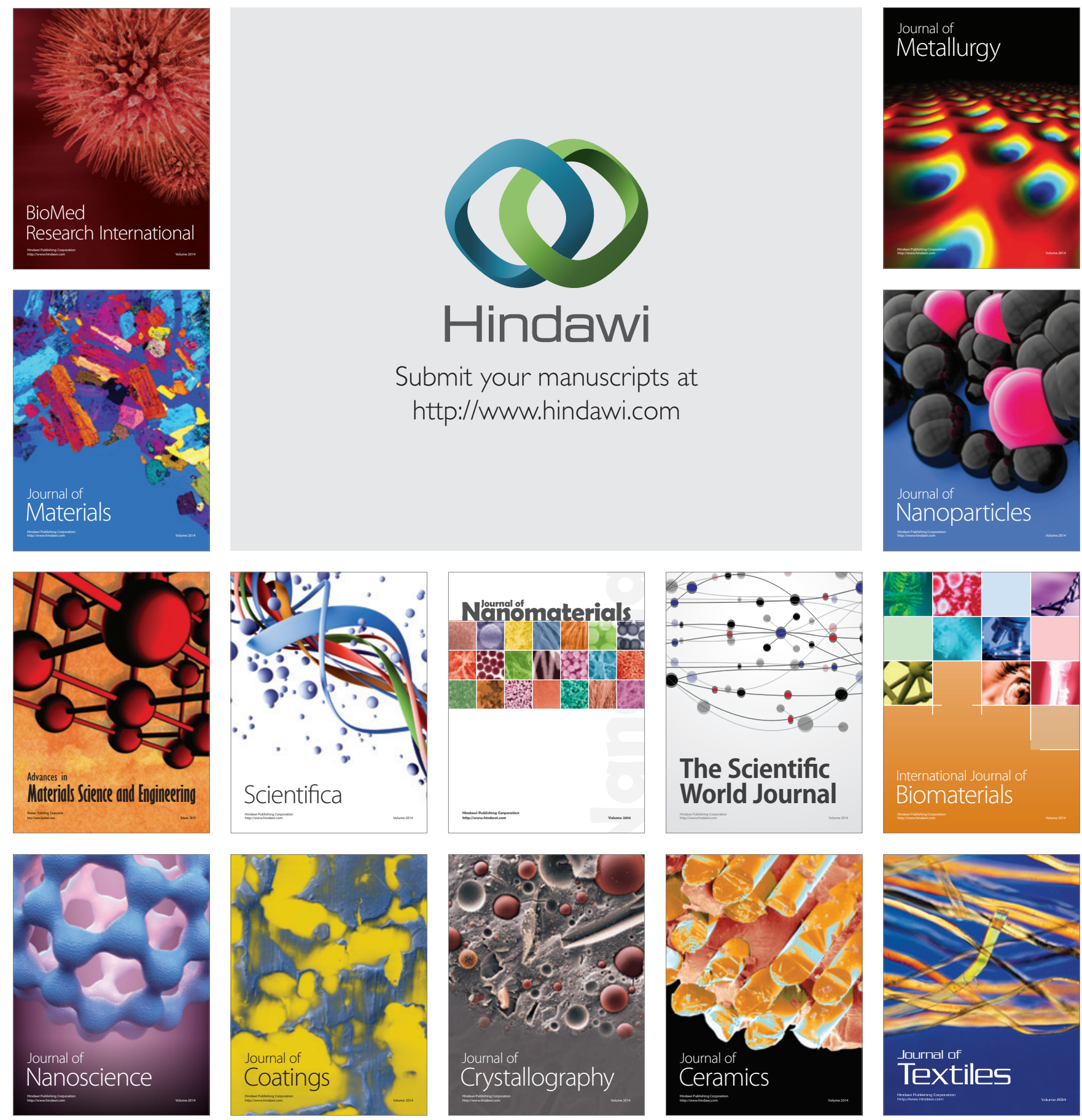